the Isthmus and Brazil was to shoot a stoneheaded arrow into the vessel. This method is also found in New Guinea. Venesection is employed in the armpit, the forehead, the vertex and various other parts of the body. In Peru the veins at the root of the nose were opened. The use of the cupping vessel is widespread.

The stopping of a blood-vessel presents diffi. culties; but the methods employed are amazing in their variety, including powdered gum, charcoal, ashes, eagle's down, bandages of bark, coconut fibre, etc. A kind of tourniquet of bark cloth is recorded in Loyalty Islands, Tahiti, Samoa and Tonga. The prevalent method of cleansing wounds among the American Indians was by sucking out the pus, a method which gave the shaman opportunity to display his magic power by showing a pebble which he had sucked from the wound.

While it has been shown from the examples quoted above that the primitive peoples of America had a certain idea of rational surgical procedure, the remainder of the primitive world, with few exceptions, did not exhibit the same degree of surgical appreciation. The races and tribes of Africa who practise an advanced procedure have derived their knowledge from other races-all tribes south of the Sahara, for example, have been influenced by Arabian surgery. There is, however, a remarkable number of mutilations which involve a certain knowledge of surgery. These are usually ritualistic in origin, such as circumcision (male and female) and infibulation. There are no less than fourteen different methods of operating on the male genitalia employed in various parts of the primitive world. Among other forms of mutilation is amputation of the fingers, which was practised by the Aurignacian peoples of palæolithic times and is recorded by imprints on rocks in California, Arizona, Peru, Africa and Australia. Cicatrisation is also a sacrament. Other mutilations in a variety of forms are practised on the nose and cheeks. Piercing the tongue is not common, but excision of the tongue is practised in West Africa.

A review of the subject leads to the belief that the resistance of primitive people is abnormal, compared with that of modern civilised races. Their apparent indifference to pain and the infrequency of blood-poisoning indicate that modern races pay for their civilisation in terms of lessened resistance, pathology and neurology.

The lecturer expressed his acknowledgments to Dr. R. Moodie and Dr. L. Freeman.

\title{
Artificial Production of a New Kind of Radio-Element
}

\section{By F. Joliot and I. Curie, Institut du Radium, Paris}

COME months ago we discovered that certain $D$ light elements emit positrons under the action of $\alpha$-particles ${ }^{1}$. Our latest experiments hare shown a very striking fact: when an aluminium foil is irradiated on a polonium preparation, the emission of positrons does not cease immediately, when the active preparation is removed. The foil remains radioactive and the emission of radiation decays exponentially as for an ordinary radioelement. We observed the same phenomenon with boron and magnesium ${ }^{2}$. The half life period of the activity is $14 \mathrm{~min}$. for boron, $2 \mathrm{~min}$. $30 \mathrm{sec}$. for magnesium, $3 \mathrm{~min}$. $15 \mathrm{sec}$. for aluminium.

We have observed no similar effect with hydrogen, lithium, beryllium, carbon, nitrogen, oxygen, fluorine, sodium, silicon, or phosphorus. Perhaps in some cases the life period is too short for easy observation.

The transmutation of beryllium, magnesium, and aluminium $\alpha$-particles has given birth to new radio-elements emitting positrons. These radioelements may be regarded as a known nucleus formed in a particular state of excitation; but it is much more probable that they are unknown isotopes which are always unstable.

For example, we propose for boron the following nuclear reaction :

$$
{ }_{5} \mathrm{~B}^{10}+{ }_{2} \mathrm{He}^{4}={ }_{7} \mathrm{~N}^{13}+{ }_{0} n^{1}
$$

${ }_{7} \mathrm{~N}^{13}$ being the radioactive nucleus that disintegrates with emission of positrons, giving a stable nucleus ${ }_{8} \mathrm{C}^{13}$. In the case of aluminium and magnesium, the radioactive nuclei would be ${ }_{15} \mathrm{P}^{30}$ and ${ }_{14} \mathrm{Si}^{27}$ respectively.

The positrons of aluminium seem to form a continuous spectrum similar to the $\beta$-ray spectrum. The maximum energy is about $3 \times 10^{6} \mathrm{e.v}$. As in the case of the continuous spectrum of $\beta$-rays, it will be perhaps necessary to admit the simultaneous emission of a neutrino (or of an antineutrino of Louis de Broglie) in order to satisfy the principle of the conservation of energy and of the conservation of the spin in the transmutation.

The transmutations that give birth to the new radio-elements are produced in the proportion of $10^{-7}$ or $10^{-6}$ of the number of $\alpha$-particles, as for other transmutations. With a strong polonium preparation of 100 millicuries, one gets only about 100,000 atoms of the radioactive elements. Yet it is possible to determine their chemical properties, detecting their radiation with a counter or an ionisation chamber. Of course, the chemical reactions must be completed in a few minutes, before the activity has disappeared.

We have irradiated the compound boron nitride (BN). By heating boron nitride with caustic soda, gaseous ammonia is produced. The activity separates from the boron and is carried away with the ammonia. This agrees very well with the hypothesis that the radioactive nucleus is in this case an isotope of nitrogen.

When irradiated aluminium is dissolved in 
hydrochloric acid, the activity is carried away with the hydrogen in the gaseous state, and can be collected in a tube. The chemical reaction must be the formation of phosphine $\left(\mathrm{PH}_{3}\right)$ or silicon hydride $\left(\mathrm{SiH}_{4}\right)$. The precipitation of the activity with zirconium phosphate in acid solution seems to indicate that the radio-element is an isotope of phosphorus.

These experiments give the first chemical proof of artificial transmutation, and also the proof of the capture of the $\alpha$-particle in these reactions ${ }^{3}$.

We propose for the new radio-elements formed by transmutation of boron, magnesium and aluminium, the names radionitrogen, radiosilicon, radiophosphorus.

These elements and similar ones may possibly be formed in different nuclear reactions with other bombarding particles : protons, deutrons, neutrons For example, ${ }_{7} \mathrm{~N}^{13}$ could perhaps be formed by the capture of a deutron in ${ }_{6} \mathrm{C}^{12}$, followed by the emission of a neutron.

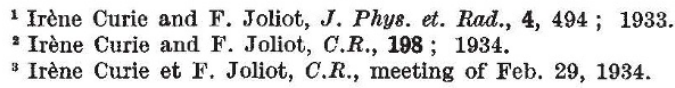

${ }^{1}$ Irène Curie and F. Joliot, J. Phys. et. Rad., 4, 494 ; 1933.

2 Irène Curie and F. Joliot, C.R., 198; 1934.

${ }^{3}$ Irène Curie et F. Joliot, C.R., meeting of Feb. 29, 1934.

\section{Obituary}

Sir Donald MacAlister, Bart., K.C.B.

$\mathrm{B}^{\mathrm{x}}$ $Y$ the death at Cambridge on January 15 of Sir Donald MacAlister of Tarbert, in his seventy-ninth year, a great personality has passed out of the academic and medical life of Great Britain. He was a Scottish highlander descended from the MacAlisters of Tarbert in Argyllshire, a family which for about five centuries possessed considerable lands in Kintyre and the heads of which were hereditary keepers of Tarbert Castle. Although originally a branch of the great clan MacDonald, they held their Tarbert possessions in charter from the Campbells with whom they cast in their lot in politics and war.

Sir Donald MacAlister was born in Perth on May 17, 1854, and received his school education there and in Aberdeen and Liverpool, the changes in family residence being necessitated by his father's business activities. In 1873 he entered St. John's College, Cambridge, and in 1877 was senior wrangler and first Smith's prizeman in addition to receiving many other University distinctions. A year later he was elected a fellow of his college and having meantime turned to the study of medicine he graduated M.B. in 1881 and M.D. in 1884. Settling in Cambridge as a consulting physician, he was appointed Linacre lecturer on physic and a member of the staff of Addenbrooke's Hospital and thus became actively engaged in medical teaching. His earliest professional studies had been in the domain of pathology, but this was soon superseded by pharmacology and therapeutics, subjects in which he retained a keen and active interest to the end. In recognition of his special attainments he was chosen president of the Section of Therapeutics at the Toronto meeting of the British Medical Association and for many years was chairman of the "British Pharmacopœia" Committee, the 1898 and 1914 editions of which owed a great deal to his collaboration.

Although deeply interested in scientific and medical research and keenly appreciative of their results, Sir Donald MacAlister was never a 'research worker' in the ordinary sense of the term. His cast of mind and abilities were more those of the statesman and administrator and it was in these directions that he found a congenial field for his activities and that he reached his highest distinction. In Cambridge he took a large share in the administrative work of the University and in 1889 was elected its representative on the General Medical Council. He soon became one of its most influential members and when he resigned from it last year on account of failing health, he had served for forty-four years, twenty-seven of which were in the presidential chair. As president his advice was frequently sought by the Privy Council and other Government departments concerned with the administration of medical education, pharmacy and the public health, and in these matters he gradually came to exercise a farreaching influence.

It was, however, not in medical matters only that Sir Donald MacAlister's influence on higher education and its administration was felt. His exceptionally wide knowledge and culture rendered him highly sympathetic to all the many departments of university studies and activities; this led to his being chosen chairman of the Universities Bureau of the British Empire, chairman of the Commission on the University of Belfast, and to much other similar public work. In 1907 he was appointed by the Crown to the high office of Principal of the University of Glasgow and shortly thereafter was made K.C.B. In 1924 he was created a baronet in recognition of his many public services. When he went to Glasgow he had no special acquaintance with Scottish university affairs, but in a surprisingly short time he had acquired a complete grasp of them no less in their business than in their teaching aspects, and this soon found expression in numerous changes and reforms. During his principalship he inspired such confidence in the citizens of Glasgow that money was freely forthcoming for the establishment of many new chairs and lectureships and for general university expansion. Nor were the social and athletic sides of student life overlooked. A new Union costing $£ 65,000$ was built, new playing fields were provided and three residential halls for men and one for wromen were acquired by the University. From many contributors he received personally a large sum of money which was devoted to the building of a chapel in memory 